\section{Funcionalismo translinguístico e cognição: relações entre corpo e gramática das línguas}

Cross-linguistic functionalism and cognition: relations between body and grammar of languages

Leosmar Aparecido da SILVA (UFG) leosmarsilva@hotmail.com

Vânia Cristina CASSEB-GALVÃO (UFG) vaniacassebgalvao@gmail.com

Recebido em: 18 de maio de 2018. Aceito em: 09 de jul. de 2018.
SILVA, Leosmar Aparecido da; CASSEB-GALVÃO, Vânia Cristina. Funcionalismo translinguístico e cognição: relações entre corpo e gramática das línguas. Entrepalavras, Fortaleza, v. 8, n. esp., p. 45-62, set. 2018

Resumo: Este artigo tem o objetivo de fazer um estudo funcional-tipológico de alguns sistemas linguísticos para verificar como esses sistemas utilizam partes do corpo humano em sua morfossintaxe. Esse objetivo está alinhado à hipótese da mente corporificada da Linguística Cognitiva, que considera que as operações mentais e linguísticas estão ancoradas no corpo humano. Analisando o sistema dêitico, as construções indicativas de movimento e o sistema de classificadores de algumas línguas, observou-se que palavras e morfemas que indicam partes do corpo humano integram a gramática dessas línguas. Trabalhos dessa natureza, além de contribuírem para se ter acesso a dados de línguas faladas por minorias, contribuem para desconstruir teses racionalistas que dicotomizam mente e corpo.

Palavras-chave: Corpo. Cognição. Gramática. 
v. 8 (esp.)

45-62

set.

2018

Abstract: This paper aims to describe some linguistic systems from typologicalfunctionalist perspective to verify how these systems use parts of the human body in their morphosyntax. This goal is aligned with Cognitive Linguistics embodied mind hypothesis, which considers that mental and linguistic operations are anchored in the human body. We analyze the deitic system, the movement constructions and the system of classifiers of some languages. The data showed that words and morphemes that indicate parts of the human body integrate the grammar of these languages. Works of this nature contribute to deconstructing rationalist theses that dichotomize mind and body and also contribute to access data on languages spoken by minorities people.

Keywords: Body. Cognition. Grammar.

\section{Introdução}

O funcionalismo linguístico, por conceber que o modo de organização das línguas é mediado por aspectos sociais, culturais e cognitivos, estabelece diálogo com os estudos da linguística cognitiva. Um desses diálogos é com a hipótese da mente corporificada (embodiedmind), defendida por Lakoff eJohnson ([1980] 2002), Johnson (1987), Lakoff (1987), Casasanto (2011), Kövecses (1992, 2005, 2009) e outros. Para esses estudiosos, o corpo é o elemento empírico que acompanha o homem em todas as suas atividades diárias e que, por isso, o ajuda a conceptualizar o mundo à sua volta. Assim, o modo como o homem vê o mundo se deve, em grande parte, à estrutura de seu corpo.

Para Le Breton (2011), o corpo é o eixo da relação com o mundo, o lugar e o tempo nos quais a existência toma forma por meio da fisionomia particular que cada indivíduo tem. Assim, o corpo tem papel fundamental na configuração das emoções, nas relações interpessoais, na realização de trabalhos, na realização de atos de fala. A gramática das línguas não está dissociada do corpo humano e das relações que ele estabelece com o mundo. Gibbs (2006), por exemplo, defende que associações do corpo em ação, principalmente relacionadas às atividades orais e à cabeça, são fundamentais para se buscar o domínio-fonte de certas estruturas linguísticas. Levantar as sobrancelhas pode revelar uma expressão de surpresa e desconforto e um ato de fala específico pode acompanhar essa ação do corpo.

Em vista dessas considerações, o objetivo deste texto é fazer um estudo funcional-tipológico para verificar em dados de diferentes línguas do mundo a hipótese da mente corporificada, por meio da qual se procura provar que o corpo está implicado na gramática das línguas, e não apenas nos atos de fala que requerem o corpo, enquanto materialidade. Propõese, portanto, verificar como o corpo, partes do corpo ou a remissão por inferência ao corpo serve de referência para categorizar o mundo por meio da estrutura gramatical e construir significados. 
Optou-se pelo funcionalismo-tipológico, porque, por meio desse subtipo das correntes funcionalistas, é possível ladear línguas de diferentes famílias e verificar diferenças e semelhanças em relação a um tema específico - no caso deste texto, o corpo - com o propósito de "descobrir qual a visão de mundo cada comunidade possui e como ela representa essa realidade linguisticamente" (SILVA, 2011, p. 27). Além disso, continua Silva (2011), o funcionalismo-tipológico, assim como os outros funcionalismos, considera os efeitos culturais, sociais e históricos sobre a língua para que ela se configure tal qual se mostra.

Para atingir o objetivo proposto, organizou-se o artigo em três seções. Na primeira seção, estabelece-se relação entre o corpo e o sistema dêitico de algumas línguas indígenas. Na segunda seção, faz-se um estudo das construções indicativas de movimento em algumas línguas e a implicação do corpo nessas construções. Na terceira seção, procura-se demonstrar como o sistema de classificadores de línguas do mundo integram o corpo.

\section{Corpo e sistema dêitico}

A palavra dêixis vem do grego e significa mostrar, apontar. É, portanto, a faculdade que utiliza a língua para designar mostrando, ao invés de conceituar. A enunciação, ato de fala único e jamais repetido, instaura no discurso um eu, que enuncia de um lugar, aqui, e de um tempo, agora, específicos. A enunciação é, portanto, o lugar do ego (eu), hic (aqui) e nunc (agora). Esses três elementos só adquirem significado numa situação comunicativa, por isso, são categorias dêiticas porque não conceituam objetivamente um referente, mas o mostra na situação discursiva.

Fillmore (1997) define dêixis como o nome dado às propriedades formais dos enunciados que são determinadas por certos aspectos do ato comunicativo em que os enunciados em questão podem representar um papel. Dentre esses papéis, estão incluídos: 1) a identidade dos interlocutores em uma situação de comunicação, a que se dá o nome dêixis de pessoa; 2) o lugar ou lugares em que esses indivíduos estão alocados, ao qual se dá o nome dêixis de lugar; 3) o tempo em que o ato comunicativo ocorre, chamado dêixis de tempo; 4) a matriz do material linguístico com a qual o enunciado tem um papel, isto é, as partes anteriores e posteriores do discurso, que é chamada dêixis discursiva; 5) as relações sociais dos participantes na conversação, que determinam, por exemplo, a escolha de níveis de fala como polidas/difamantes, íntimas/formais. Essas relações podem ser agrupadas sob o termo de dêixis social. Para este trabalho, interessam as dêixis de pessoa, de lugar e de tempo. 
v. 8 (esp.)

45-62

set.

2018

Castilho (2010, p. 123-125) resume o pensamento de alguns importantes linguistas em relação ao fenômeno da dêixis, como se verifica no quadro 1 :

\section{Quadro 1 - A dêixis para os linguistas, segundo Castilho (2010) \\ LINGUISTA \\ CONSIDERAÇÃO TEÓRICA SOBRE DÊIXIS}

Apolônio Díscolo (séc. I d. C.)

Bühler (1934/1961)

Câmara Jr. (1977, p. 90)

48
Os pronomes de $1^{\mathrm{a}}$ e $2^{\mathrm{a}}$ pessoas servem para discernir pessoas ainda não definidas, com o que as pessoas por eles significadas se fazem definidas.

As expressões linguísticas se dividem em simbólicas e em dêiticas. Os símbolos são referencialmente estáveis. A dêixis depende da situação de fala em que está ancorada. A dêixis representa o primeiro conhecimento da coisa. Através da propriedade dêitica, inserimos entidades na corrente do discurso. O segundo conhecimento ocorre quando retomamos, via foricidade, essas mesmas entidades. Diferentes classes gramaticais codificam a dêixis: os pronomes, os advérbios de tempo e de lugar, certos morfemas e outros.

A dêixis é a faculdade que tem a linguagem de designar mostrando, em vez de conceituar. A designação dêitica, ou mostrativa, figura assim ao lado da designação simbólica ou conceitual em qualquer sistema linguístico. Podemos dizer que o signo linguístico apresenta-se em dois tipos: o símbolo, em que um conjunto sônico representa ou simboliza, e o sinal, em que o conjunto sônico indica ou mostra.

Benveniste (1966, p. 84) Os dêiticos constituem uma irrupção do discurso no interior da língua, porque o seu próprio sentido [...] embora revele da língua, apenas se pode definir por alusão ao seu emprego.

Ducrot / Todorov (1972 / 1998, p. 302)

Dêiticos são expressões cujo referente só pode ser determinado em relação aos interlocutores. Assim, os pronomes de primeira e segunda pessoa designam respectivamente a pessoa que fala e aquela a quem se fala.

Lyons (1979, p. 290) Todo enunciado linguístico se realiza num lugar particular e num tempo particular: ocorre numa certa situação espaço-temporal. É produzido por uma pessoa - o falante - e em geral se dirige a alguma outra pessoa - o ouvinte.

Lahud (1979, p. 40) A noção de dêixis está muito vinculada à classe linguística dos pronomes pessoais (eu/você, mais precisamente), pronomes demonstrativos (isso) e formas temporais do verbo.

Fonte: adaptado de Castilho (2010). 
Castilho (2010) distingue dêixis e foricidade. Segundo o autor (2010, p. 125), a foricidade é "a operação desencadeada, sobretudo, por itens lexicais que trazem de novo à consideração noções já identificadas anteriormente (anáfora), ou a serem veiculadas posteriormente (catáfora) no texto." Já a dêixis depende da situação em que palavras como eu, este/esse, aqui, hoje; você, esse/este, aí, amanhã; ele, aquele, lá, outrora, entre outras, foram veiculadas. Sentenças como "Pedro veio para a casa de José" ou "Pedro foi para a casa de José" podem ser consideradas dêiticas, uma vez que os verbos ir e vir dão pistas contextuais de onde está o enunciador: na casa de José, no primeiro caso, e em outro lugar diferente da casa de José, no segundo caso. Assim, a dêixis "só existe ancorada em algum contexto social" (FILLMORE, 1997, p. 59).

Nos termos de Benveniste (2005), a presença de um eu que se alterna com um tu instaura na conversação as pessoas presentes no discurso. A presença desses pronomes evidencia a subjetividade na linguagem, uma vez que eles remetem ao sujeito enunciador, em torno do qual as relações espácio-temporais se organizam.

Diante dessas considerações, pergunta-se: qual o lugar do corpo nessas definições de dêixis?

Abraçado (2011, p. 208) defende a ideia de que o fenômeno da dêixis "constitui um elo entre o mundo ambiental e a gramática de uma língua." Citando Armstrong, Stokoe e Wilcox (1995), a autora destaca que o gesto foi um elemento importante para a evolução da linguagem.

Para Abraçado (2011), numa perspectiva não inatista, a aquisição da linguagem não pode ser explicada sem se considerar a relação entre o mundo ambiental e os seres humanos que nele habitam. Daí a importância do corpo de um eu/tu que se constituem o centro das relações espácio-temporais que se dão à sua volta. O corpo social de um indivíduo também contribui para a significação do universo discursivo construído por meio da sintaxe. Além disso, o fenômeno da dêixis, que tem um centro enunciativo encarnado num corpo biológico, corrobora a hipótese funcionalista, segundo a qual a pragmática é o berço da sintaxe, tal como afirmaram Sankoff e Brown (1976) apud Abraçado (2011).

Como forma de analisar melhor esse fenômeno, serão apresentados dois exemplos: a dêixis na língua Tapirapé e na língua Sateré-Mawé. ${ }^{2}$

\footnotetext{
${ }^{1}$ Essa língua é falada por uma comunidade indígena no estado de Mato Grosso, Brasil. 2 Língua do tronco Tupi, conforme classificação de Aryon D. Rodrigues. É falada nos estados do Pará e do Amazonas, Brasil.
} 
v. 8 (esp.)

45-62

set.

2018

Segundo Leite (1998, p. 90), em Tapirapé, "é a perspectiva do falante que comanda o uso das formas; é preciso que os fatos relatados estejam no âmbito de sua visão e tenham sido por ele presenciados".

Como prova disso, Leite (1998) mostra que a partícula rãka, indicadora de passado, só pode ser usada com a primeira pessoa. É um tipo de evidencial, ou seja, indica que o falante presenciou a ação e que ela se realizou efetivamente. Ações praticadas no passado por outra pessoa são indicadas pelo uso de rõ'õ rã'e. Ações não realizadas, por motivos relacionados à pessoa que fala, são descritas por meio da partícula pane.

Segundo Praça (2007, p. 100), na língua Tapirapé, "os demonstrativos espaciais são proformas que revelam uma relação intrínseca entre a forma/posição e a localização do referente em relação ao falante". Isso significa que os demonstrativos, além de indicarem localização espacial, indicam também forma e posição, segundo a perspectiva do falante, com o seu corpo, que é o ponto de referência para a indicação de forma e posição dos objetos, animais etc. Praça (2007, p. 100) resume os demonstrativos descritos por Leite (1998) em (01):

50

(01)

ekwe

próximo/distante

"comprido" / "chato" 'ã /epe

próximo/distante

"redondo" 'yn /ewin (ou' /ewĩ)

próximo/distante

"alto"

Dessa forma, segundo Leite (1998), o tucunaré é alto, se estiver parado e se é visto de dentro de uma canoa por uma pessoa em pé. Se o peixe se movimentar, sua forma toma outra perspectiva para o observador que, consequentemente, utilizará outra forma linguística.

Ainda em relação à localização espacial, a noção de longe ou lá deve também estar dentro dos limites da visão do falante.

Nas línguas românicas, não há a necessidade de marcar o beneficiário de eventos como cheguei!, choveu!. Em Tapirapé, porém, ele é marcado. Segundo Leite (1998, p. 97, grifo da autora), em Tapirapé, "a lanterna acende para alguém, chega-se para alguém, vai-se para alguém, morre-se de alguém", conforme se verifica em dado de Paula (2010, p. 292):

(02) _ _ Ãã ka newi.

$\begin{array}{llll}\tilde{\mathrm{A}}=\tilde{\mathrm{a}}- & \text { ka } & \text { ne }- & \text { wi } \\ 1^{\mathrm{a}} \text { ps } & \text { ir agora } & 2^{\mathrm{a}} \text { ps.- } & \text { proc } \\ \text { '(Eu) me vou agora de você'. } & & \end{array}$


Exemplos como o de Paula (2010) e os de Leite (1998) mostram o quanto a enunciação em Tapirapé estabelece diálogo entre o eu, o outro e a realidade circundante. Isso reforça a proposta de Abraçado (2011) de que a dêixis constitui-se um elo entre o mundo físico e o mundo linguístico e que as representações da língua não são simplesmente 'objetos de discurso', desconectadas da realidade física. Leite (1998), citando Lima (1996), afirma que não há realidade independente do sujeito. E mais: se tanto a realidade quanto o sujeito se manifestam na língua, não há realidade independente do sujeito assim como não há realidade e sujeitos independentes da língua.

Já a língua Sateré-Mawé, conforme afirmação de Franceschini (2005, p. 60), "apresenta um sistema bastante complexo de dêiticos demonstrativos." Esses dêiticos podem ser classificados em dois grupos:

1) os que indicam entidades materiais percebidas como um todo, ${ }^{3}$ que podem ser verificadas no quadro 2 , a seguir:

Quadro 2 - Dêiticos demonstrativos do Sateré-Mawé

CODIFICAÇÃO
indicam
o todo
da
entidade

VALOR SEMÂNTICO

Ko entidades suspensas/penduradas (frutas, cacho de banana); entidades que se encontram no ar (pássaro, avião) ou na água (barco).

Sup entidades que se encontram em posição horizontal e que possuem uma forma alongada/comprida (quadrúpedes, cobra etc).

nU entidades que se encontram em posição vertical e que se encostam a uma superfície (animais sentados - cachorro, porco); objetos arredondados ou planos que se encontram sobre uma superfície (prato sobre a mesa, cuia no chão).

Indicam parte da Me indica que o referente está próximo do enunciador. entidade

Meu indica que o referente está longe do enunciador.

Fonte: Adaptação de Franceschini (2005).

2) os que indicam entidades não materiais, como no dado a seguir:

mio

Os dados a seguir mostram duas situações. Na primeira (03), o demonstrativo faz referência a um lápis que está sobre a mesa em posição horizontal e que está sendo tocado pelo enunciador. Na segunda (04), o interlocutor está segurando o lápis na mão.

\footnotetext{
${ }^{3}$ Nesse grupo, existem ainda morfemas dêiticos que indicam entidades percebidas como parte de um todo, como me $\sim$ meu.
} 
v. 8 (esp.)

45-62

set.

2018
(03) me: -sup

dem.P.2

'Este lápis é meu.'

(04) me: -ke

dem.M.1

'Este lápis é meu.' lapi $\quad \mathrm{u} \quad-\mathrm{i} \quad-$ wat

lápis 1p.s. + rel. + rd.nm.gen.

O que se pode perceber nesses dados é que o enunciador, como centro dêitico, tem fundamental importância para a construção da referência espacial das entidades e a posição física em que tais entidades se encontram.

A presença do enunciador como ponto de referência em relação às entidades é fundamental para mostrar que seu corpo, como representação concreta da categoria pessoa, localizado num tempo e num espaço específicos, contribui para a formação do conceito de dêixis na gramática das línguas naturais.

Feita essa breve descrição entre corpo e dêixis, na próxima seção, relacionamos corpo e construções de movimento.

\section{O corpo implicado em construções indicativas de movimento}

Uma das experiências mais básicas realizada com o corpo é o movimento. Gibbs (2006, p. 43), citando Dewey (1896), diz que o movimento corporal é anterior à sensação. Isso porque, quando se lê, quando se caça, quando se realiza uma experiência química, o que fornece o estímulo é o ato como um todo. Há ocorrência de estímulos motores e sensoriais de forma simultânea, mas, se não houvesse o estímulo motor, o sensorial não seria percebido. O reconhecimento de objetos, por exemplo, passa pelas ações praticadas com tais objetos, a partir de procedimentos exploratórios diretos. Assim, para perceber as propriedades de um objeto tais como a textura e a forma, é essencial o movimento das mãos; para conhecer a maciez, a dureza ou a maturação de um alimento é preciso movimentar o maxilar. Para o autor, perceber frequentemente atividades de outras pessoas ativa o cérebro, de modo a corresponder à ativação provocada pela atividade desempenhada.

$\mathrm{Na}$ língua, o movimento corporal pode ser codificado, principalmente, por verbos de ação e de processo. Devido ao processo de gramaticalização desenvolvido pelos verbos ir e vir, esses verbos merecem atenção especial. "Ir e vir contribuíram para a construção da 
noção de futuridade e de perfectividade nas línguas, respectivamente", tal como afirma Givón (1989, p. 57). Tornaram-se, portanto, marcadores de tempo (vou estudar) e de aspecto (A Teresa vem me tratando com indiferença). A mudança envolveu extensão metafórica do sentido de movimento espacial de ir e vir para movimento temporal e aspectual, uma vez que, no processo de gramaticalização, é comum o "desbotamento" semântico. A extensão metafórica ocorrida na mudança de ir e vir depende, segundo Givón (1989, p. 58), da seguinte inferência pragmática: ir indica "afastamento deste lugar; futuro indica afastamento deste tempo". Da mesma forma, vir indica mover-se em direção a este lugar; perfectivo indica mover-se em direção a este tempo. $\mathrm{O}$ movimento físico realizado no espaço e o movimento mental realizado no tempo têm como referência o corpo do falante situado num espaço e num tempo, tal como foi visto na seção 1, sobre corpo e deixis. Para Givón (1989), ir é um movimento que revela afastamento do falante e vir, aproximação, ambos em relação a um lugar.

Ribeiro (2002, p. 39), ao descrever o sistema direcional do Karajá4, afirma que, nessa língua, a categorização de direção não é feita por meio de opostos direcionais lexicais como no inglês come x go e bring $\mathrm{x}$ take. A categorização de direcionalidade, que implica movimento, em Karajá, é feita por mecanismos morfológicos. Em (5a, b), a seguir, o prefixo $r$ - (ou sua alomorfia zero) indica que o evento (indicado pela raiz verbal -a-) ocorre em direção oposta ao lugar em que o falante está. Essa direção é chamada "centrífuga" (CTFG). Já o prefixo d- (realizado como [n] antes de nasais e/a) indica que o evento ocorre na direção onde falante se encontra. É chamada "direção centrípeta" (CTPT). Os dados de Ribeiro (2002, p. 39), a seguir, mostram a sobreposição de movimento no espaço e futuridade:

(5a) krakre

$\mathrm{ka}-\mathbf{r}-\varnothing-\mathrm{a}=$ kəre

1-CTFG-INTR-move $=$ FUT

'I will go' . (Eu irei) (5b) kanakre

ka $-\mathrm{d}-\varnothing-\mathrm{a}=$ kəre

1-CTPT - INTR - move $=$ FUT

'I will come' (Eu virei)

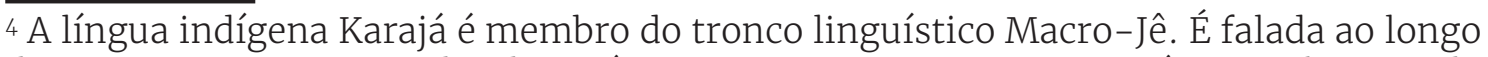
do Rio Araguaia, nos estados de Goiás, Mato Grosso, Tocantins e Pará - Brasil. Segundo Ribeiro (2002), ela tem quatro dialetos: O Karajá do Sul, o Karajá do Norte, Javaé e Xambioá. Juntando os falantes dos quatro dialetos, há um total de aproximadamente 3.000 falantes.
} 
v. 8 (esp.)

45-62

set.

2018

Tanto em (5a) como em (5b), o corpo do falante é o ponto de referência para a realização do evento. Em (6a, b), o mesmo verbo ("lo" - "entrar) pode ser flexionado ora com morfema indicativo de direção centrífuga ora com morfema indicador de direção centrípeta. Em (6a), o falante está fora de casa, por isso, usa a direção centrífuga. Em (6b), marcado pela direção centrípeta, o falante está em casa. Vejamos:

(6a) maloke

$\mathrm{b}-\boldsymbol{\varnothing}-\mathrm{a}-\mathrm{l} 0=\mathrm{k} \boldsymbol{E}$

2-CTFG-INTR-enter=POT

'Enter!' (Entre!) (6b) manaloke

bə $-\mathbf{d}-\mathrm{a}-\mathrm{l} 0=\mathrm{k} \varepsilon$

2-CTPT-INTR-enter $=$ POT

'Enter!' (Entre!)

Segundo Talmy (2000), o movimento pode ser factivo, ou real, quando um objeto se desloca num espaço, ou fictício, quando imageticamente existe a suposição de que ocorreu o deslocamento de um objeto.

Verbos como ir, vir, deixar, no sentido de afastar-se, podem ser representativos do movimento factivo no léxico, assim como substantivos deverbais como ida, vinda, afastamento, e também preposições como de, desde, a, para.

Já o movimento fictício pode ocorrer, segundo Castilho (2010, p. 619), nos diferentes níveis de análise linguística. No nível fonético, uma consoante pode movimentar-se no interior da sílaba, como em pergunto > pregunto, ou de uma sílaba para outra, como em os olhos $>$ o zolho. Na morfologia, um morfema pode flutuar em diferentes componentes do sintagma, como em os menino bonito/ os meninos bonito / os meninos bonitos. Na sintaxe do Português, o objeto pode mover-se de sua posição prototípica (à direita do verbo) para o início da sentença como em A torta, o Francisco comeu. A função sintática sujeito que, em Português, normalmente, encabeça a sentença, pode ser movido para depois do verbo, como em Veio o Francisco. Além disso, os clíticos também se movimentam para antes ou para depois do verbo, como em Me disseram ou disseram-me. Na semântica, é comum o movimento fictício, considerado uma metáfora, como se verifica em Nossa vida nos levou longe ou Nossa vida é um barco. No discurso, o uso fictício do movimento pode ser elucidado por atos de fala que indicam modalidade como: quépará? (< quer parar), pópará (< pode parar?). 
Em Castilho (2010, p. 262), a palavra "transitividade" (do latim transitiuus), usada para mostrar a relação entre verbos e argumentos, é a manifestação da categoria cognitiva movimento. Para o autor, em algum momento, os gramáticos entenderam que a língua representa um tipo de percurso ${ }^{5}$ e que a sentença pode ser vista como lugar de passagem, em que a ação passa do agente para o paciente. Esse entendimento parte do protótipo dos verbos, que é o verbo de ação. Na mesma direção, Furtado da Cunha (2008, p. 2), citando Slobin (1982), afirma que o evento transitivo prototípico é aquele em que "um agente animado intencionalmente causa uma mudança física e perceptível de estado ou locação em um paciente através de contato corporal direto". Afirma ainda que "são esses eventos que a criança percebe e codifica gramaticalmente mais cedo, partindo, depois, da codificação desses para a codificação dos eventos menos típicos".

Os dados do Karajá descritos nesta seção e as considerações de Castilho (2010) e de Furtado da Cunha (2008) sobre transitividade contribuem para a constatação do fato de que são inúmeros os casos de usos da língua que contribuem para se compreender o corpo como fornecedor de material cognitivo para o sistema conceptual humano e para a codificação de fenômenos na gramática.

A seguir, última seção deste texto, relacionamos corpo e o sistema de classificadores de algumas línguas.

\section{O corpo e o sistema de classificadores das línguas}

Classificadores são morfemas que indicam a classe semântica ou morfológica de palavras ou expressões. Segundo Aikhenvald (2000, p. 1) "todas as línguas têm alguns significados gramaticais para a categorização de nomes e nominativos". O termo 'classificadores', segundo a autora, é um rótulo usado para uma ampla gama de dispositivos de categorização. Acrescenta que diferentes tipos de classificadores podem ser distinguidos por seu status gramatical, grau de gramaticalização, condições de uso, significado, tipos de origem, modo de aquisição etc. Formato, animação, dimensão, mobilidade, status são exemplos de algumas das bases semânticas nas quais os classificadores se assentam.

Um classificador pode apenas categorizar o nome por ele mesmo, como no exemplo da língua Yidiny, falada na Austrália:

${ }_{5}^{5}$ Metáfora do conduto ou canal (REDDY, 1979). 
v. 8 (esp.)

45-62

set.

2018

\section{(07) bama waguja \\ CL:PERSON man \\ 'a man' (um homem)}

Os classificadores surgem de itens lexicais de classes abertas (nome, verbo) ou de uma subclasse de classes abertas (nomes próprios, verbos de ação etc.). É mais comum, entretanto, que os classificadores tenham origem em nomes do que em verbos. Segundo Aikhenvald (2000, p. 353), eles envolvem gramaticalização de um item lexical para um marcador gramatical ou poligramaticalização, em que um item lexical dá origem a mais de um marcador gramatical.

Conforme as informações tipológicas e teórico-descritivas apresentadas, o uso de partes do corpo envolve processos metonímicos geralmente definidos pelas partes salientes do corpo. Segundo Aikhenvald (2000), 'cabeça' e 'olhos' são as mais frequentemente usadas como classificadores nas línguas indígenas. É caso, por exemplo, do Xerente $^{6}$, que, segundo Siqueira (2010, p. 131), tem a partícula kwa, cujo significado primitivo é 'dente' e cujo significado derivado é 'instrumento que corta'. Essa partícula ocorre, por exemplo, na palavra kwamh que significa 'injeção'. Nesse uso, kwa- estende seu estatuto semântico e se constrói na língua e na mente do falante como um item com função classificadora. Daí, objetos semelhantes ao dente serem categorizados linguisticamente a partir dessa base ou fonte de produção de sentidos.

Existem classificadores de vários tipos: nominais, verbais, numéricos, locativos, mensurais, possessivos, de espécie, dêiticos, relacionais e outros.

Segundo Aikhenvald (2000), dentre os classificadores que se gramaticalizam a partir de partes do corpo estão os verbais, numerais, mensurais, de espécie e locativos. Com base em dados apresentados por Aikhenvald (2000, p. 355-7), apresenta-se a seguir um quadro contendo o tipo de classificador, a língua a que ele pertence, o dado propriamente dito, o tipo de coisa que ele classifica e a parte do corpo correspondente ao uso gramaticalizado:

${ }_{6}^{6}$ Língua indígena do estado do Tocantins, Brasil. 
Quadro 3 - Tipos de classificadores que gramaticalizam partes do corpo

\begin{tabular}{|c|c|c|c|c|}
\hline $\begin{array}{c}\text { TIPO DE } \\
\text { CLASSIFICADOR }\end{array}$ & LÍNGUA & EXEMPLO & REMISSÃO & $\begin{array}{l}\text { PARTE DO } \\
\text { CORPO }\end{array}$ \\
\hline $\begin{array}{l}\text { CLASSIFICADORES } \\
\text { VERBAIS }\end{array}$ & Ianomami ${ }^{7}$ & ko & $\begin{array}{l}\text { 'Objetos } \\
\text { redondos' }\end{array}$ & 'coração' \\
\hline $\begin{array}{l}\text { CLASSIFICADORES } \\
\text { NUMÉRICOS }\end{array}$ & Palikur $^{8}$ & uku/wok & $\begin{array}{c}\text { 'coisas } \\
\text { contáveis' }\end{array}$ & 'mão' \\
\hline & & k'et & 'punhado' & 'mão' \\
\hline $\begin{array}{l}\text { CLASSIFICADORES } \\
\text { MENSURAIS }\end{array}$ & $\begin{array}{l}\text { Tzotzil } 9 \\
\text { Hmong }\end{array}$ & jan & $\begin{array}{l}\text { 'termo usado } \\
\text { para medir } \\
\text { roupas' }\end{array}$ & 'dedo' \\
\hline \multirow[t]{2}{*}{$\begin{array}{l}\text { CLASSIFICADORES } \\
\text { DE ESPÉCIE }\end{array}$} & Bahnar ${ }^{11}$ & kol & $\begin{array}{c}\text { 'seres vivos, } \\
\text { pessoas, } \\
\text { escravos, } \\
\text { barcos e objetos } \\
\text { de valor, termo } \\
\text { que denigre } \\
\text { seres humanos' }\end{array}$ & 'cabeça' \\
\hline & & măt & $\begin{array}{c}\text { 'título } \\
\text { honorífico } \\
\text { para seres } \\
\text { humanos' }\end{array}$ & $\begin{array}{c}\text { 'olhos, } \\
\text { menina } \\
\text { dos olhos' }\end{array}$ \\
\hline $\begin{array}{l}\text { CLASSIFICADORES } \\
\text { LOCATIVOS }\end{array}$ & Palikur & -kigsa & $\begin{array}{l}\text { 'no topo/ } \\
\text { cume de coisas } \\
\text { pontudas' }\end{array}$ & 'nariz' \\
\hline
\end{tabular}

Aikhenvald (2000, p. 353-4) afirma que as partes do corpo são o subgrupo semântico dos nomes que mais frequentemente se gramaticaliza como classificadores verbais.

Assim, em relação aos classificadores verbais, eles se caracterizam por aparecerem no verbo, mas categorizam um nome, que é tipicamente um sujeito de verbos intransitivos ou objetos de verbos transitivos. O classificador verbal pode indicar forma, consistência, animacidade, tamanho, estrutura, posição, constituição e extensão, propriedades físicas, função e organização. Um exemplo de classificador verbal da língua Waris, fornecido por Aikhenvald (2000, p. 3) é morfema put-, que indica 'objetos redondos'. Em (08), é associado ao verbo dar para caracterizar seu objeto direto 'coco':

\footnotetext{
7 Língua falada na fronteira entre o Brasil e a Venezuela.

${ }^{8}$ Língua falada por povo indígena que vive no estado do Amapá, Brasil.

9 Língua Maia, falada no México.

${ }^{10}$ Grupo de dialeto falado no Vietnã, Tailândia e Laos.

${ }^{11}$ Língua falada por aproximadamente 700.000 pessoas no Vietnã, Cambódia e Laos.
} 
v. 8 (esp.)

45-62

set.

2018
(08) sa

Coconut ka-m put-ra-ho-o

1SG-to VCL:ROUND-GET-BENEFACT-IMPERATIVE

'Give me a coconut' (lit. 'coconut to-me round.one-give')

'Dê-me um coco' (lit. 'coco para-mim redondo.um-dê')

Ao descrever esse tipo de classificador nas línguas Mundurukú e Tariana $^{12}$, Borges (2001, p. 7) $)^{13}$ afirma que o classificador $a$, no Mundurukú usado para 'cabeça, coisa arredondada', que aparece em (09), ocorre no sintagma nominal sujeito - uk3'a2 -, no sintagma adjetival - yazdip2 e na forma verbal, em que tal classificador se refere a uk3'a2, por meio de sua característica mais relevante: o arredondamento. Segue o dado:

$$
\begin{aligned}
& \text { (09) } U_{k 3}{ }^{-} \quad \text { 'a } 2 \quad y^{-} \quad a_{3} \quad \operatorname{dip} 2 \quad 0^{-} y^{-} \boldsymbol{a 2}^{-} \text {muy3 } \\
& \mathrm{n}-\mathrm{nc} \quad \mathrm{pr}-\mathrm{nc}-\text { at } \mathrm{ps}-\mathrm{pr}-\mathrm{nc}-\text { estar } \\
& \text { casa-redonda ela - redonda - bonita ela - dela - redonda - estar } \\
& \text { 'A casa redonda estava bonita' (cf. GONÇALVES, 1987, p. 52) }
\end{aligned}
$$

A propriedade física da casa - ser arredondada - é codificada linguisticamente por meio da mesma partícula que designa uma parte do corpo - a cabeça - que também tem o formato arredondado.

Em relação aos classificadores numéricos, eles aparecem contíguos a expressões de quantidade. Segundo Aikhenvald (2000, p. 98), a escolha deles é predominantemente semântica e, ao contrário dos outros classificadores, eles podem ser gramaticalizados (pertencerem a classes fechadas) ou podem pertencer a classes lexicais abertas. As oposições semânticas empregadas em classificadores numéricos variam. Elas envolvem com maior frequência animacidade, forma, tamanho e estrutura. Podem também ser um classificador genérico, que pode ser usado com quase todo nome. Um exemplo está no Mandarin Chinês, em que o classificador Ge é genérico e constitui forma independente.

(10) sān

Three

Ge

'three person' ('três pessoas') rén

person

\footnotetext{
${ }^{12}$ A língua indígena Mundurukú é falada nos estados do Pará e do Amazonas, Brasil. A língua Tariana é falada no estado do Amazonas, Brasil.

${ }^{13} \mathrm{Na}$ descrição do sistema de classificadores do Mundurukú, Borges apóia-se em Gonçalves (1987).
} 
Os classificadores mensurais constituem um tipo específico de classificadores numerais. Os mensurais são aqueles que individualizam entidades em termos de quantidade. São usados para medir unidades, nomes contáveis e massa. Nas línguas, os classificadores mensurais normalmente estão relacionados à mão e suas partes. Em Tzotzil, falada no México, por exemplo, k'et 'punhado' é usado para se referir a uma pilha de grãos de qualquer espécie. No português, não há um sistema de classificadores mensurais, mas itens lexicais plenos relativos a partes do corpo como polegada, pé, braça normalmente são usados. Tais medidas, conforme informações de fontes históricas, surgiram inicialmente no Egito e se espalharam para outros povos. A unidade mais usada era o côvado, a distância do cotovelo até a ponta do dedo médio, que corresponde a 66 centímetros. Segundo dados de medidas internacionais, 1 polegada equivale a 25.401 milímetros ou 2.5401 centímetros; 1 pé equivale a 0.3048 metros e $\mathbf{1}$ braça corresponde a 1.8288 metros. $^{14}$

Os classificadores de espécie categorizam espécies como seres vivos, seres humanos, barcos, objetos de valor, em grande parte, usando partes do corpo como morfema classificador. É o caso da língua Bahnar, em que kol ('cabeça') é usado para seres vivos, pessoas, escravos. E também para animais, barcos e objetos de valor, assim como é usado para desqualificar seres humanos. Por fim, em relação aos classificadores locativos, segundo Aikhenvald (2000), são aqueles que se utilizam de partes do corpo para indicar lugar. A partícula -kigsa 'cume de coisas pontudas', por exemplo, está relacionada com -kig 'nariz'.

Essa breve incursão em línguas do mundo sobre classificadores que gramaticalizam partes do corpo parece ser suficiente para endossar a hipótese cognitivista de que a conceptualização e a apreensão do mundo, via cognição, tem forte componente corporal.

\section{Considerações finais}

No decorrer deste texto, verificou-se, inicialmente, a relação entre corpo e sistema dêitico. A conexão entre mundo linguístico e mundo físico é intermediada pela dêixis de pessoa, de espaço e de tempo, principalmente. Considerou-se que, ao caracterizar um organismo como 'pessoa', o falante adota a perspectiva da primeira pessoa - o seu corpo, o seu 'eu' - e, a partir desse centro dêitico, todo o restante das

14 Fonte: http://www.infoescola.com. 
v. 8 (esp.)

45-62

set.

2018

outras pessoas é caracterizada como tal (GIBBS, 2006). Isso mostra que os seres humanos são capazes de refletir sobre eles mesmos por meio de mecanismos cognitivos e de conceptualizar seus corpos e estados mentais como seus. Têm, além disso, consciência do espaço e do tempo circundantes em que ocorre o ato de fala.

Posteriormente, verificou-se que o eu, pessoa do discurso, dotada de um corpo físico, é também o centro daquilo que Ribeiro (2002) chamou de força centrífuga e força centrípeta, no sistema direcional da língua Karajá.

Por fim, constatou-se que corpo também está em evidência em morfemas gramaticalizados como classificadores verbais, numéricos, mensurais, de espécie e locativos em várias línguas do mundo.

Os dados parecem, então, confirmar a hipótese da mente corporificada, proposta por estudiosos da linguística cognitiva. O que se postula com isso, porém, não é exclusivamente a participação do corpo no modo de conceber e categorizar o mundo, por meio do léxico e da gramática, mas se atesta que o conhecimento do mundo se dá de modo empírico, por meio dos sentidos corporais. Uma vez aprendida determinada noção, tende-se a estender o sentido para outros contextos, por meio de mecanismos cognitivos como a metonímia e a metáfora. É, portanto, uma proposta teórica alternativa que se opõe ao racionalismo puro, à lógica cartesiana, ao inatismo, e coloca em destaque o pensamento imaginativo e a subjetividade.

\section{Referências}

ABRAÇADO, J. Como é possível vivermos e convivermos em um mundo real e nos comunicarmos exclusivamente no âmbito de um universo discursivo? Alfa [online], São Paulo, Vol. 55. n. 1., P. 205-224, 2011, N. 1981-5794.

AIKHENVALD, A. Y. Classifiers: a typology of noun categorization devices. Oxford: Oxford University Press, 2000.

BENVENISTE, E. Problemas de linguística geral I. Trad. de Maria da Glória Novak e Maria Luisa Neri. Rev. Isaac Nicolau Salum. 5 ed. Campinas, SP: Pontes Editores, 2005.

BORGES, M. V. Classificadores verbais em Mundurukú e Tariana. Trabalho de final de curso. São Paulo: UNICAMP, 2001.

CASASANTO, D. Different Bodies, Different Minds: the body-specificity of language and thought. Current Directions in Psychological Science. DOI:10.1177/0963721411422058, 2011.

CASTILHO, A. T. de. Gramática do Português brasileiro. São Paulo: Contexto, 2010. 
FILLMORE, C. Lectures on deixis. Califórnia: CSLI Publications, 1997.

FRANCESCHINI, D. Os demonstrativos em Sateré-Mawé(Tupí). In: RODRIGUES, A. D.; CABRAL, A. S. A. C. (Orgs.). Novos estudos sobre línguas indígenas. Brasília: Editora da Universidade de Brasília, 2005. p. 59-68.

FURTADO DA CUNHA, M. A. Manifestações discursivas da transitividade. Revista do Gelne. v. 4, n. 2. 2002. ISSN 2236-0883. Disponível em: <http://www. gelne.org.br/Site/RevistaGelne/arquivos/art_872982b5549900ac4e9a4420 dd8637d_17.pdf $>$. Acesso em: 30 jan. 2012.

GIBBS JR., R. W. Embodiment and cognitive science. Cambridge: CUP, 2006.

GIVÓN, T. Mind, code and context: essays in pragmatics. London: Lawrence Erlbaun Associates, 1989.

JOHNSON, M. The body in the mind: the bodily bases of meaning, imagination, and reason. The University of Chicago Press, London, 1987.

KÖVECSES, Z. Metaphor, language, and culture. D.E.L.T.A. (Revista de Documentação de Estudos em Linguística Teórica e Aplicada): Metaphor and cognition. n. esp. Vol. 1, 1/2. São Paulo: EDUC, 1992.

Metaphor in culture: universality and variation. Cambrigde: Cambridge University Press, 2005.

Universalidade versus não universalidade metafórica. Trad. Maitê Gil e Tamara Melo. Cadernos de tradução. n. 25. Jul./dez. Porto Alegre: Instituto de Letras da UFRGS, 2009. p. 257-277.

LAKOFF, G.; JOHNSON, M. Metáforas da vida cotidiana. [coordenação da tradução Mara Sophia Zanotto]. Campinas, SP: Mercado das Letras, 2002. [Primeira publicação: 1980].

LAKOFF, George. Women, fire, and dangerous things: what categories reveal about the mind. Chicago and London: The University of Chicago Press, 1987.

LE BRETON, D. A sociologia do corpo. 5 ed. Petrópolis, RJ: Vozes, 2011.

LEITE, Y. De homens, árvores e sapos: forma, espaço e tempo em Tapirapé. In: Mana [online]. Vol. 4. N. 2. ISSN 0104-9313. 1998. p. 85-103.

PAUlA, E. D. de. Saudações Tapirapé: expressões do Teka Teka. Signótica. Vol. 21. N. 2. Goiânia: Programa de Pós-Graduação em Letras e Linguística/ Faculdade de Letras. 2010. P. 279-304.

PRAÇA, W. N. Morfossintaxe da língua Tapirapé. Família Tupi-Guarani. Brasília, DF: Universidade Federal de Brasília (UNB), 2007. Tese de Doutorado.

REDDY, M. J. The conduit metaphor. In: ORTONY, A. (Ed.). Metaphor and thought. Cambridge: Cambridge University Press, 1979. p. 284-324.

RIBEIRO, E. R. Direction in Karajá. In: Memorias. VI Encuentro Internacional de Linguística en el Noroeste. Editoras: Zarina Estrada Fernández \& Rosa María Ortiz Ciscomani. Hermosillo, Sonora (México). Editorial UniSon, 2002. p. 39-58. 
v. 8 (esp.)

45-62

set.

2018

SILVA, S. B. Estudo funcional-tipológico da transitividade verbal em português do Brasil aplicado ao ensino. Dissertação de Mestrado. Universidade de Brasília: 2011.

SIQUEIRA, K. M. de F. Descrição de nomes de partes do corpo em composições lexicais na língua Akwê -Xerente. Trabalho final de disciplina. Goiânia: UFG, 2010.

TALMY, L. Toward a Cognitive Semantics. Cambridge: The MIT Press, 2000. 